\title{
NA PRÁtICA, A TEORIA É OUTRA? OS EQUívOCOS ONTO / EPISTEMOLÓGICOS NA FORMAÇÃO DE PROFESSORES EM TEMPOS DE MUNDIALIZAÇÃO DO CAPITAL
}

\section{IN PRACTICE, IS THE THEORY ANOTHER? THE ONTOEPISTEMOLOGICAL MISTAKES IN TEACHER EDUCATION CAPITAL'S MUNDIALIZATION}

\author{
Sônia Regina Landini ${ }^{1}$ \\ Silvana Galvani Claudino-Kamazaki ${ }^{2}$
}

\section{RESUMO}

Este artigo tem por objetivo identificar e discutir, à luz do materialismo histórico, as bases epistemológicas presentes nas teses que abordam a formação de professores nos cursos de licenciatura e que têm como foco a relação teoria e prática.

Palavras-chave: formação de professores - epistemologia - práxis - neopragmatismo materialismo histórico.

\begin{abstract}
This paper aims to identify and discuss, taking as support of historical materialism, the epistemological bases present in theses about graduate degree courses in teacher training that have as focus the relationship between theory and practice - práxis.
\end{abstract}

KEY WORDS: Teacher training - epistemology - praxis - neopragmatism - historical materialism.

\section{INTRODUÇÃO}

As condições sociais, econômicas, políticas e culturais atuais têm como marca a flexibilização do trabalho, associada aos processos de descentralização e às 
novas formas de controle do trabalho e do trabalhador. Processos desta natureza vêm sendo desencadeados desde o final do século XX, tendo como objetivo a manutenção da ordem capitalista. Neste sentido, reformas sociais têm sido incitadas com a finalidade de assegurar as necessárias formas de controle, formação e manutenção dos princípios primordiais do capitalismo, calcados na exploração do trabalho humano.

Nessa lógica, as reformas políticas são essenciais, o que desencadeará um modelo de Estado aos moldes da livre concorrência - neoliberalismo - cujo papel consiste em gerenciar e regular a sociedade civil. Neste contexto, as reformas educacionais têm papel preponderante por estarem relacionadas às propriedades ideológicas do capitalismo, formando sujeitos e disseminando as premissas necessárias a um novo momento de exploração do trabalho.

No Brasil, essas reformas tomam corpo a partir da década de 90 do século passado, trazendo à tona novas formas de pensar os processos de ensino-aprendizagem e as finalidades da educação escolar, ressaltando concepções epistemológicas que focalizam o professor como profissional competente, adequado e eficaz, aquele professor que permite ao aluno enfrentar problemas práticos vivenciados no cotidiano complexo e diverso por natureza. A naturalização da diversidade ocupa o lugar da crítica à sociabilidade alienada, obscurecendo a análise da propriedade privada do trabalho.

É nessa configuração social que se insere, portanto, o trabalho do professor, bem como sua formação. Necessário enfatizar que, para formar um sujeito resiliente ${ }^{3}$, capaz de lidar com as adversidades postas na cotidianidade, o professor deve, acima de tudo, ser capaz, ele próprio, de lidar com os desafios com que se depara em sala de aula e na escola.

Tais considerações nos levam a uma tendência latente nas políticas de formação de professores: a de garantir uma ação pedagógica ágil, voltada para a prática docente, perspectiva que se impõe por meio de uma forte presença da prática nos currículos de formação de professores. Além disto, como os problemas da prática refletem a diversidade de sujeitos, com culturas diversas, personalidades distintas, origem sócio econômica múltipla, privilegia-se a capacidade do professor de dominar as diferentes expressões linguísticas e culturais dos alunos. Trata-se, portanto, de uma formação capaz de lidar com as diferenças de modo prático, instrumental, objetivando 
proporcionar aos alunos o acesso aos conhecimentos básicos de códigos matemáticos, da linguagem, além da capacidade de lidar com adversidades.

A formação de professores, ao acompanhar as tendências de formação de um novo sujeito, adaptado, flexível, resiliente, passa a ter como característica primeira o domínio reflexivo sobre a prática, desígnio que tem respaldo no neopragmatismo, uma "linha de pensamento multifacetada, hábil em se harmonizar com diferentes concepções" (GONÇALVES, 2009, p.70).

O neopragmatismo caracteriza-se, no plano filosófico, por focar a busca pela verdade, assinalada pelas múltiplas narrativas, pela diversidade linguística e cultural. Trata-se de considerar que só se pode explicar a realidade pela forma como esta faz sentido aos sujeitos, sem o aporte da(s) teoria (s) ou métodos científicos. Em outras palavras, o sujeito é central, sendo a objetividade apenas a expressão de diferentes pontos de vista. Neste escopo, a formação dos sujeitos que deve ser pensada na sociedade atual é a que desconfia de narrativas prontas, fomentando a recriação e redescrições da verdade, próprias ao momento em que se insere. Assim, não há uma teoria baseada em um determinado método científico que seja capaz de explicar a realidade conjuntural, o que enseja a negação da teoria como elemento central na formação dos indivíduos. Trata-se de, como denomina Moraes (2001) um recuo da teoria, cuja

[...] negação da objetividade aparece aqui associada à ideia de desintegração do espaço público, do fetichismo da diversidade, da compreensão de que o poder e a opressão estão pulverizados em todo e qualquer lugar. Daí resulta a impossibilidade de estabelecer uma base de resistência e de enfrentamento da realidade efetiva que, queiram ou não, apresenta-se aos sujeitos enquanto totalidade da economia e das relações de poder (MORAES, 2001, p.13).

Se essas noções estão presentes na formação acadêmica em geral, a partir do recorte epistemológico em voga, no campo da formação de professores essa tendência se desenvolverá tendo ênfase na prática profissional, na experiência, também sob influência do pragmatismo, justificadas pela ineficiente formação inicial dos professores.

Com grande ênfase na formação voltada às tarefas cotidianas relacionadas ao ensinar, cujo foco central se põe no ato de tomar as dificuldades cotidianas do fazer do professor como base para respostas mais eficientes, tomando menos as teorias educacionais como referência e substituindo-as pela reflexão sobre as características 
diversas dos sujeitos - alunos - envolvidos nos processos de aprendizagem. Trata-se de uma prática reflexiva, como querem Perrenoud (1993) e Donald Schön (1992).

A questão que se evidencia para esses autores é o saber escolar, que tendo sido tomado como certo por ser baseado em conhecimentos científicos, teria desvalorizado os saberes intuitivos, espontâneos. $O$ argumento concentra-se na necessidade de transformar o foco de um processo que sai do centro para a periferia para um processo que coloque os saberes periféricos como centrais.

Nessa linha de raciocínio, o bom professor seria, para Schön (1992), aquele que busca ajudar o aluno a encontrar respostas para suas preocupações, dúvidas e angústias. Assim, o profissional formado pela prática reflexiva teria a capacidade de refletir e buscar soluções em sua ação cotidiana, vivenciada sem grandes reflexões e análises.

Importante notar que, nas proposições acima, o profissional reflexivo tem o eixo de sua formação baseado no conhecimento cotidiano em detrimento do saber escolar de base científica. O profissional reflexivo, portanto, tem como foco o aluno como indivíduo isolado, prenhe de anseios e experiências, os quais são respondidos com o fim último de sanar suas dificuldades práticas.

O que está em questão aqui é a valorização da prática como referência de vida dos indivíduos. Partir do real, da vida concreta, o que pode ter um sentido importante. No entanto, é preciso considerar, em contraposição a estas concepções, que a vida concreta não é individualizada, mas marcada pela sociabilidade. Isso exige considerar as experiências individuais como parte de um todo, o qual só pode ser compreendido com o auxílio da teoria.

Tal equívoco pôde ser detectado em estudo realizado por ClaudinoKamazaki (2013) junto ao Banco de Teses da CAPES e que teve como objeto as investigações realizadas no período de 2005 a 2010 a respeito da formação de professores nas licenciaturas que tratavam em alguma medida, da relação entre teoria e prática na formação docente.

Foram analisadas oito teses, selecionadas a partir de 72 teses sobre a formação de professores nas licenciaturas, resultado do recorte cujo foco se concentrou na relação teoria e prática.

A relação entre teoria e prática nos estudos evidenciou três tendências distintas, a saber: a primeira tem como referência a noção de práxis advinda do 
materialismo histórico dialético, com influências de Marx (1981), Vazquez (2007); a segunda, cujo foco de análise baseava-se na prática reflexiva, marcadamente centrada nas contribuições de Schön (1983), Tardif (2002) e Perrenoud (1993); a terceira, e talvez a mais importante "tendência" verificada nas teses pesquisadas, foi o que a pesquisadora chamou de incoerência epistemológica, caracterizada pela "mistura" ou "confusão" entre duas correntes antagônicas de pensamento: o Materialismo Histórico Dialético e o Neopragmatismo.

\section{FORMAÇÃO DE PROFESSORES: PRÁXIS, PRÁTICA REFLEXIVA OU CALDEIRÃO EPISTEMOLÓGICO?}

A partir dos resultados obtidos no trabalho de Claudino-Kamazaki (2013), buscaremos explicitar as três perspectivas defendidas nas Teses estudadas.

A primeira tendência, práxis docente, foi encontrada, dentre os trabalhos investigados, apenas nas Teses de Moradillo (2010) e Santos Júnior (2005).

Em Moradillo (2010) a categoria práxis é compreendida, explicitada e defendida pelo autor, de acordo com vários trechos de seu trabalho, que declara que a formação de professores deve, em sua visão, contemplar "a complexidade do conhecimento e da influência do contexto sócio-histórico na produção do conhecimento científico"(p.19). E complementa (MORADILLO, 2010, p. 26):

[...] para compreender e superar os problemas educacionais, visando à emancipação humana, a melhor alternativa encontrada foi através de uma concepção teórico-metodológica que entende a educação como parte de uma totalidade maior, que é a sociedade, e entender a sociedade é entender a história da relação homem/natureza mediada pelo trabalho, com o fim de dar conta da sua existência. Essa relação é sempre modificável no seu conteúdo e forma, dando a plasticidade tão característica do ser social. O ser social é práxis: síntese de pensamento e ação interessados. (grifos nossos)

Em oposição ao Neopragmatismo das pedagogias já citadas, o autor explicita a práxis no ato de ensinar:

O elemento norteador das discussões do ensino das ciências como práxis é a categoria trabalho, sua gênese, desenvolvimento e as mediações originadas a partir dele. Análise do trabalho no seu sentido ontológico, histórico e sua forma alienada. (MORADILLO, 2010, p. 76) 
Santos Júnior (2005) realiza uma "reflexão sobre a matriz de pensamento que serve de base para a formação de professores" ( $p$ 42), problematizando o embasamento teórico-filosófico desta formação. O autor defende o trabalho como princípio educativo, de acordo com Saviani (2003), e o estabelecimento da "prática enquanto práxis social" como eixo articulador do conhecimento na formação de professores:

[...] um projeto político-pedagógico construído coletivamente por meio da articulação ensino-pesquisa-extensão, referenciado em um projeto histórico, claro e explícito, que aponte para a superação das relações estabelecidas pelo modo capitalista de produzir e reproduzir a vida na sociedade, e que tenha como matriz científica a história e como eixo articulador do conhecimento a prática enquanto práxis social. (SANTOS JÚNIOR, 2005, p 134-5)

A segunda tendência encontrada por Claudino-Kamazaki (2013), a "prática reflexiva, neopragmatismo e epistemologia da prática" aparece em dois dos oito autores investigados, quais sejam Andrade (2006) e Peres (2007).

Andrade (2006), ao entrevistar professores do curso de formação de professores em História, discordando das respostas destes, evidencia que (p. 177)

Para o bem e /ou para o mal, se os formadores de professores formulam e fazem funcionar uma formação de conhecimento, é a partir de seus saberes experienciais que o fazem, mais do que de uma explícita manipulação de conhecimentos teóricos sobre a formação. (grifos nossos)

Embora criticando o pensamento pós-moderno que invade a área da educação e defendendo a teoria, o autor afirma a importância de uma Oficina de Formação Docente para o Ensino de História onde a teoria seja levada a um plano menor, sobrevalorizando os saberes experienciais e a cultura escolar.

Posicionamento semelhante foi identificado no trabalho de Peres (2007) para quem há uma ênfase na relação entre teoria e prática nas propostas advindas da epistemologia da prática que permitem a superação dessa dissociação. Deste modo, ao criticar a racionalidade técnica, propõe a epistemologia da prática tendo em vista que:

[...] as discussões relativas aos problemas enfrentados por esses profissionais em sua atuação cotidiana ficam em segundo plano. Superar isso requer desfazer a relação mecânica e linear entre o conhecimento teórico e a prática em sala de aula, e em seu lugar estabelecer uma relação em que a teoria e prática possibilitem ao futuro professor refletir sobre os problemas e sobre as dinâmicas geradas por sua atuação na prática (PERES, 2007, p 46). 
Ainda, defendendo os argumentos de Schön (2000) quanto à formação profissional através do "ensino prático reflexivo desenvolvido por meio da reflexão-naação”, Peres afirma (2007 p 44-5).

$\mathrm{Na}$ epistemologia da prática que envolve a reflexão-na-ação, além da aplicação rotineira de regras já estabelecidas, há também, no processo de resolução de problema, a resposta por meio da invenção imediata de novas regras, ou seja, nesses casos, há respostas para o inesperado, por meio de invenções e experimentos imediatos para testar novas compreensões.

Em síntese, tanto Andrade (2006) quanto Peres (2007) estão referenciados na proposta neopragmática da prática reflexiva como alternativa viável para a articulação entre teoria e prática na formação docente, talvez sem se aperceberem dos limites desta proposta que, dentre outras coisas, viabiliza apenas uma "reflexão" a partir da realidade aparente, cotidiana, alienada.

A terceira tendência - incoerência epistemológica - reflete uma confusão entre práxis e prática reflexiva que está presente em quatro dos oito trabalhos investigados, quais sejam as Teses de Pereira (2005), Campos (2006), Cesário (2008) e Melo (2007).

Pereira (2005) afirma que “(...) podemos, a partir da definição de prática e práxis, concluir que a prática é proveniente da experiência e que necessita ser transformada através da reflexão para se tornar práxis. E práxis só ocorre quando há unidade entre teoria e prática. (p 32) (grifos nossos). No entanto, reivindica uma formação pautada nos saberes experienciais:

Temos que levar em consideração que os professores em formação valorizam as experiências, pois acreditam que serão estas que irão formá-los, porém ao chegar ao curso se assustam com a separação existente entre a formação teórica e prática no currículo da formação inicial. (PEREIRA, 2005, p. 11) (grifos nossos)

E, complementando, afirma que para

Quando pensamos a educação como práxis é fundamental a relação entre os conhecimentos e os saberes docentes. Na construção dos saberes docentes é importante tanto a teoria como a prática. Defendemos uma relação dialética entre a teoria e prática, isto é, a unidade de uma teoria educativa com uma prática educativa. Espera-se que o professor hodierno saiba questionar e reconstruir, mas, para isso, é necessário ter a capacidade de saber pensar. (PEREIRA, 2005, p. 44) (grifos nossos) 
Por sua vez, o trabalho de Campos (2006) a respeito de como são realizadas as 800 horas de prática nos cursos de Licenciatura de uma Universidade de São Paulo reflete, por um lado, a legítima preocupação de todos os autores pesquisados quanto à articulação entre teoria e prática na formação docente e, de outro, uma equivocada analogia entre práxis e prática reflexiva, como se fossem complementares entre si.

Seu discurso inicial parece apontar para a crítica à prática reflexiva, ancorada no "enfoque dialético" que diz assumir em sua investigação.

\begin{abstract}
Assumo as características da dialética na pesquisa pretendida ao buscar construir um conhecimento a partir de estudos referentes à prática nos cursos de formação de professor, entendendo que essa ação pode ser constantemente revista e sobre a qual sempre podemos refletir, num movimento dialético de reflexão-ação. Uma reflexão que parte da ação para voltar a ela, desvendá-la e transformá-la (CAMPOS, 2006, p 18). (grifos nossos)
\end{abstract}

Todavia, seu texto vai revelando que a autora toma a práxis como prática reflexiva, conforme afirma

\begin{abstract}
Pensar sobre o desenvolvimento de um currículo de formação de professores sobre o ponto de vista da práxis é prever, além da teoria (associada ao conhecimento) e da prática (muitas vezes associada à habilidade), uma atitude investigativa que promova a reflexão $e$ a intervenção crítica e produtiva em face da realidade de atuação (com os professores, os alunos, a escola e a sociedade em que o professor está inserido). Desse modo, esperase confrontar teoria e prática, entendendo sua importância na realização de um currículo que promova a profissionalidade do professor como ponto principal de sua formação (CAMPOS, 2006, p 28-30). (grifos nossos)
\end{abstract}

Neste sentido, a prática reflexiva está presente na caracterização de profissionalidade adotada pela autora. Para Campos (2006 p 46)

[...] as reflexões sobre a prática docente aparecem como campo de formação em que o conhecimento específico, confrontado com a realidade e os problemas cotidianos, levam a novas considerações e constatações teóricas, podendo favorecer a reconstrução prática, constituir um processo de formação como contínuo e contribuir para a profissionalização docente.

Cesário (2008) também elege a prática reflexiva como referência para a formação do professor e sua profissionalização (p 23):

A formação profissional baseada na epistemologia da prática ao valorizar e refletir sobre a experiência constitui-se como um momento importante de construção de conhecimentos. Por meio da reflexão, análise e problematização da experiência, busca-se reconhecer o conhecimento tácito, presente nas soluções que os profissionais encontram em suas ações.

Embora haja diferenças entre algumas abordagens, o paradigma da prática reflexiva tem como ideia comum que a formação inicial deve incluir um 
praticum reflexivus, ou seja, constituir-se num espaço de formação em que o futuro professor tenha oportunidade de refletir constantemente a dinâmica e os problemas gerados por sua atuação cotidiana.

Mas a incoerência epistemológica aparece novamente quando a autora indica a presença da racionalidade prática nas Diretrizes Curriculares para formação de professores como um avanço, uma vez que esta prática, nestes documentos, "não é vista como um modelo aplicacionista, mas como um espaço de produção dos saberes e de formação para os saberes" (CESÁRIO, 2008, p 29) e em seguida complementa:

\begin{abstract}
Embora essa visão não represente a compreensão da maioria dos professores da área, conforme abordado anteriormente, para nós ela representa o entendimento de que a Educação Física está inserida no contexto da Educação e, assim, valorizada juntamente com os demais saberes curriculares escolares, é responsável pela formação de cidadãos compromissados com as mudanças sociais. Isso indica que o professor deve ter uma sólida base de conhecimentos científicos durante seu período de formação profissional, na direção de aprender a ensinar em diferentes contextos sociais e para diferentes alunos. (CESÁRIO, 2008, p 46). (grifos nossos)
\end{abstract}

Ao defender "uma sólida base de conhecimentos científicos", ao mesmo tempo em que se assume ser partidária da prática reflexiva, Cesário (2008) não se apercebe que esta última faz parte das propostas neopragmáticas que valorizam o conhecimento tácito em detrimento do conhecimento teórico/científico.

Por fim, dentre os trabalhos pesquisados, a Tese de Melo (2007) foi aquela em que a indisciplina teórica fez morada, haja vista a mistura de argumentos que apresenta.

Após anunciar sua investigação que busca "dar voz" aos sujeitos envolvidos nos cursos pesquisados, Melo afirma que (2007 p. 44)

[...] compreender os processos formativos, as experiências, as trajetórias de vida, permite esclarecer uma série de questões que vão desde a forma como o professor ensina, quanto ao modo como ele organiza os conteúdos, os procedimentos e como lida com os alunos. Isso faz com que se valorize outro tipo de saber: o experiencial, aquele que brota da experiência, sendo validado por ela $(\ldots)$

Tal posicionamento é seguido da argumentação da autora quanto à importância da articulação entre teoria e prática na formação docente em que a autora cita a práxis, inclusive referenciando-a a partir do materialismo histórico em nota de rodapé. 
Esse posicionamento dos autores (Fiorentini, 2001 e Carr \& Kemmis, 1988) nos faz compreender a prática pedagógica como uma verdadeira práxis, ou seja, momento em que teoria e prática são absolutamente indissociáveis. Polarizar na formação de professores ora a ênfase na teoria, ora na prática seria cometer um equívoco (MELO 2007, p 46).

Ainda, logo após fazer duras críticas à "logica das competências" presente nas Diretrizes, Melo ressalta (2007, p. 78):

É oportuno ressaltar que os saberes não são aqui tomados no mesmo sentido de competências, uma vez que isso reduziria esse conceito. Os saberes docentes ultrapassam a aquisição de competências, vão além do mero conhecer para aplicar, pois são saberes elaborados que o professor constrói ao longo de sua formação e de sua prática. Além disso, o termo competência é aberto a várias interpretações, é polissêmico e, quando utilizado em substituição dos saberes, contribui para uma desvalorização profissional dos professores.

A autora parece não reconhecer que tanto as propostas de Perrenoud (1999) quanto às propostas de Tardif (2002) estão ancoradas nos mesmos referenciais neopragmáticos que sobrevalorizam a prática em detrimento do embasamento teóricocientífico.

A indisciplina teórica está presente, por fim, na apresentação dos resultados de sua pesquisa, haja vista a concordância da autora com concepções antagônicas de educação, a exemplo dos trechos a seguir (MELO 2007, p 123 e 126)

[...] a razão científica não pode se contrapor à razão pedagógica e vice-versa. Os saberes docentes são igualmente importantes, sem desconsiderar que o ponto de partida para a formação de professores é, justamente, o aprendizado dos saberes disciplinares [...].

[...] O aprofundamento teórico das questões pedagógicas deverá ser evidenciado nos cursos de licenciatura, mas a partir de uma prática dialética que permita a compreensão da realidade escolar. Será a partir desse movimento, de romper com o processo mecânico de ensino em que a teoria se encontra dissociada da prática, que se propõe um processo de compreensão de teoria e prática como dois lados de um mesmo objeto.

Da mesma forma, podemos encontrar críticas à racionalidade prática anteriormente defendida, como nos trechos seguintes (MELO 2007, p 179-80):

Schön (1992) apresenta, ainda, o modelo da "racionalidade prática", que visa superar a relação mecânica e linear entre o conhecimento científico e a prática escolar. Nessa perspectiva, o ponto de partida é a análise da prática dos professores, na busca de se compreender como utilizam o conhecimento científico e como enfrentam situações complexas, inerentes ao processo ensino-aprendizagem. O papel da teoria, nesse modelo, é oferecer diferentes interpretações para a compreensão da realidade, sendo possível, a partir dessa compreensão, modificar a prática. 
No entanto, Carr e Kemmis (1988), inspirados na teoria sociocrítica, consideram que essa forma de explicar a relação teoria-prática é insuficiente. Para esses autores, a teoria contribui para alterar a consciência que se tem da realidade social.

Complementado seus argumentos, Melo (2007) faz considerações contrárias às proposições vinculadas à racionalidade prática, anteriormente defendida a partir das propostas de Tardif (2002)

\begin{abstract}
O entendimento da relação teoria-prática, a partir de uma visão dialética, em que teoria e prática são interdependentes, nos leva a crer que o grande desafio da formação de professores é romper com essa dissociação entre a teoria distanciada da realidade e a prática desprovida de teoria [...] é preciso uma formação que tenha como pressuposto a interseção entre teoria e prática, que permita ao futuro professor a capacidade de identificar os determinantes sociais mais amplos que interferem em sua prática, bem como, perceber-se como sujeito histórico do processo ensino-aprendizagem, capaz de analisar, criticar e transformar a realidade escolar, em razão de um determinado projeto educativo no qual ele acredite (MELO 2007, p 180).
\end{abstract}

Claudino-Kamazaki (2013) destaca que todos os autores pesquisados, sem exceção, empreendem legítimos esforços para tentar estabelecer a indissociabilidade entre teoria e prática na formação de professores, compreendendo a importância da prática nos cursos de formação, prática esta historicamente negligenciada em virtude da hegemonia da racionalidade técnica durante muito tempo.

Reconhece também a dificuldade em articular teoria e prática sem que se corrobore com a crítica à teoria e sem cair em seu oposto, ou seja, na defesa da racionalidade prática, igualmente fragmentada.

Cabe evidenciar que a epistemologia da prática profissional defendida por Tardif (2002) destaca os saberes experienciais construídos na prática ou "o conjunto dos saberes utilizados realmente pelos professores em seu espaço de trabalho cotidiano para desempenhar sua tarefa" (TARDIF, 2002, 10), estes saberes "temporais, plurais, heterogêneos, personalizados, situados" deveriam, segundo Tardif, ocupar lugar central nos cursos de formação de professores, num modelo de formação "segundo uma lógica profissional centrada no estudo das tarefas e realidades do trabalho dos professores" (TARDIF, 2002, p 13-19)

Tal modelo coloca claramente em segundo plano o conhecimento acadêmico, científico, teórico que, para Tardif (2002, p 21) "não vale nada do ponto de vista da ação profissional” em virtude de um conhecimento tácito, construído na prática, daí tratar-se de uma epistemologia ancorada no Neopragmatismo, em que: 
[...] qualquer ideia de ciência como conhecimento objetivo do real é inteiramente descartada. O Neopragmatismo vê a ciência como "um tipo de literatura", propõe a literatura e as artes como investigação, no mesmo patamar da investigação científica. A ciência comporia apenas um dos setores da cultura - e nem mesmo o mais privilegiado ou interessante (MORAES, 2003 p 176).

Conforme aponta Gonçalves (2009) tendo a prática como fundamento, o pragmatismo é uma espécie de "guarda-chuva" que contempla outras concepções antiintelectuais e que têm como tendência a desconsideração por abstrações. Em sua versão renovada a partir da última década do século $\mathrm{XX}$, o neopragmatismo continua se caracterizando como "uma linha de pensamento multifacetada" que, dentro outros aspectos, negam a ciência como explicação da realidade (relativismo científico) e defendem a cultura e a língua como definidoras do ser (e não as relações sociais).

Perrenoud $(1993,1996,1999)$ também caminha nesta direção, na medida em que propõe a profissionalização do professor, questionando o papel da Universidade nesse processo e valorizando, da mesma forma que Tardif (2002), os saberes distintos dos conhecimentos universitários, as competências que, segundo o autor:

[...] são capacidades de ação, que mobilizam saberes para a ação, que estabelecem relações com os saberes teóricos que não são de reverência ou dependência, mas ao contrário, são críticas, pragmáticas, até mesmo oportunistas (PERRENOUD, 1996 p. 135).

Este enfoque no conhecimento ligado à ação do professor - um conhecimento tácito, cotidiano - também se encontra na Pedagogia do professor reflexivo de SCHÖN (1983, 2000), que o denomina de reflexão-na-ação e conhecer-naação. O próprio autor define este conhecimento tácito como

[...] espontâneo, intuitivo, experimental, conhecimento cotidiano, do tipo revelado pela criança que faz um bom jogo de basquetebol, [...] ou que toca ritmos complicados no tambor, apesar de não saber fazer operações aritméticas elementares. Tal como um aluno meu me dizia, falando de um seu aluno: Ele sabe fazer trocos, mas não sabe somar os números. (SCHÖN, 1997, p 82)

Cabe salientar que o cotidiano é, desta forma, considerado uma categoria estanque, que se basta a si mesma, diferente do que postula o Materialismo Histórico Dialético. Nesta perspectiva, sendo contraditório, o cotidiano precisa de uma teoria que sustente a análise de sua contradição, ou seja, a análise da realidade contempla a consideração da sua complexidade e deve ir além da mera descrição das rotinas das 
práticas sociais, em geral, e das relações interpessoais, em particular, como nos indica Heller (1994) e requer o movimento que vai do concreto ao concreto pensado, de acordo com o método dialético, algo que a prática reflexiva não alcança.

Desta forma, a prática reflexiva defendida por estes autores se constitui numa proposta oposta à perspectiva do materialismo histórico, que:

[...] pressupõe ir além da aparência do fenômeno, buscando revelar as relações dinâmico-causais reais subjacentes e captar as mediações que o determinam e o constituem, contribuindo para que o concreto abstrato transforme-se em concreto pensado, "uma rica totalidade de determinações e relações diversas" (MARX, 1978b, p.116). Neste sentido, caracteriza-se fundamentalmente enquanto análise do processo e não do objeto, sendo, portanto, uma análise explicativa e não descritiva. (SILVA, SILVA e MARTINS, s/d, p. 5)

$\mathrm{Na}$ perspectiva do materialismo histórico dialético, a práxis educativa tem como função desvelar a realidade contraditória a fim de realizar a emancipação da consciência, necessária para a transformação da realidade social. Para tanto, um dos principais fundamentos da filosofia da práxis defendida por Marx, para quem "toda ciência seria supérflua se houvesse coincidência imediata entre a aparência e a essência das coisas” (MARX, 1981, p 939) é a superação da análise fenomênica da realidade.

Conforme afirma Vázquez (2007 p 146)

[...] a prática não fala por si mesma e os fatos práticos - como todo fato - têm de ser analisados, interpretados, já que não revelam seu sentido à observação direta e imediata, ou a uma apreensão intuitiva. O critério da verdade está na prática, mas só é descoberto em uma relação propriamente teórica com a própria prática.

Nesse contexto, a prática é, para Marx, expressão objetiva do fazer, mediada pelo conjunto da produção histórica, na relação sujeito-objeto. Portanto, o materialismo histórico dialético define prática como expressão da ação subjetiva, sempre mediada pela história humano-objetiva, concepção inequivocamente contrária à prática utilitária definida pelo pragmatismo.

\section{CONSIDERAÇÕES FINAIS}

A noção de que a teoria não consegue se por na prática parece ser uma falácia que adentra o campo acadêmico e tem provocado equívocos analíticos. A 
influência do pensamento pós-moderno na Educação vem fortalecendo este pressuposto, haja vista a desconsideração de qualquer teoria científica que explique a realidade, algo que pudemos observar em grande parte dos trabalhos investigados por ClaudinoKamazaki (2013).

A crítica à ciência moderna, a suposta positividade da racionalidade prática como substitutiva da racionalidade técnica - como se ambas não representassem, em essência, a mesma fragmentação do conhecimento - assim como a valorização das "resoluções para os problemas do cotidiano" parecem não ser percebidas, a exemplo de seis dos oito trabalhos investigados por Claudino-Kamazaki (2013), apenas como uma nova forma de alheamento dos trabalhadores - inclusive os da Educação - que passam a ter acesso a mais conhecimento, porém, um conhecimento raso, restrito às suas necessidades utilitárias, práticas, baseado numa "reflexão sobre a ação" isenta de uma leitura ampla dos determinantes da realidade social e escolar, como quer a prática reflexiva, de cunho claramente neoliberal.

Sob o ponto de vista neopragmático, a compreensão da realidade em sua totalidade torna-se irrelevante, a exemplo da prevalência da crítica fenomênica nos trabalhos pesquisados, crítica esta que não ultrapassa sua análise superficial.

Nessa perspectiva, a reflexão proclamada como um momento imprescindível da atividade docente, não ultrapassa a avaliação individual sobre o trabalho realizado e não capta todas as determinantes de seu resultado.

A relação entre teoria e prática presentes nestas pedagogias neopragmáticas se distingue sobremaneira da práxis enquanto categoria do materialismo histórico que implica em capturar da realidade objetiva, concreta, todos os seus determinantes, analisá-la pela consciência (abstrações) para se chegar ao concreto pensado, prenhe de escolhas para o alcance de um fim, no sentido de alterar a realidade encontrada.

Ademais, cabe destacar que a carência de domínio teórico-metodológico, evidenciado pela mistura de linhas de pensamento antagônicas - Neopragmatismo e Materialismo Histórico Dialético - foi o mais significativo "achado" da pesquisa de Claudino-Kamazaki (2013).

Tal constatação nos leva a acreditar que há um grave comprometimento no processo de formação de professores e dos formadores de professores, fortalecido pela falta de consciência dos mesmos a esse respeito. Podemos inferir que a ênfase nas "práticas" em detrimento da teoria, incorre, consequentemente, no "praticismo" de seus 
defensores ou, como já denunciavam Moraes e Torriglia (2000, p. 53), esta “[...] construção empiricista da experiência induz ao relativismo e à passividade e à aceitação de todo o status quo".

Neste sentido, bem assevera Moraes (2003)

\begin{abstract}
Toda teoria [...] tem consequências tanto negativas como positivas. Em seu lado positivo, a teoria pode oferecer-nos as bases - racionais e críticas - para rejeitar muito do que hoje nos chega como consenso ou como sabedoria política realista [...]. Ela pode nos fazer compreender que o pseudo-realismo que conforma o "pensamento único" não apenas é construído ideologicamente (...), mas representa interesses socioeconômicos e políticos precisos, encobertos sob a roupagem de um espúrio apelo populista aos valores do individualismo consumista. Por outro lado, [...] a teoria pode promover o ceticismo generalizado sobre as questões do conhecimento, da verdade e da justiça, uma visão que os torna, ao fim e ao cabo, ininteligíveis e absurdos, trazendo como consequência a paralisia e uma boa dose de irracionalismo (MORAES, 2003, p. 163-164).
\end{abstract}

As teorias pós-críticas “enredadas ao domínio da prática" defendidas em seis dos oito trabalhos investigados pó Claudino-Kamazaki (2013), caminham nesta esteira da "despolitização do campo educacional" que vem trazendo o congelamento da análise da Educação em suas inúmeras contradições, bem como esse ceticismo generalizado apontado por Moraes (2003), além do espontaneismo e do praticismo (DENTZ, 2011, p. 368).

Este comprometimento comum identificado na maioria dos trabalhos investigados nos permite concluir, a partir da "crítica ontológica" (DENTZ, 2011), que não há possibilidade de uma proposição crítica que tenha como embasamento um aporte epistemológico que não confira concretude ao fenômeno estudado, ou seja, uma análise epistemológica deve estar ancorada na compreensão ontológica, que depende da historicidade, dos conhecimentos acumulados pela humanidade e cientificamente estruturados, da totalidade das relações sociais.

\title{
REFERENCIAS BIBLIOGRÁFICAS
}

ANDRADE, E. P. Um Trem rumo às estrelas: a oficina de formação docente para o ensino de História - o curso de História da FAFIC. Tese de Doutorado. Niterói (RJ), 2006. disponível em http://www.uff.br/pos_educacao/joomla/images/stories/Teses/andradet2006.pdf

BRANDÃO, J. M; MAHFOUD, M; GIANORDOLI-NASCIMENTO, I.F. A construção do conceito de resiliência na psicologia: discutindo as origens. Paideia. Vol. 21, No. 49, 
maio-agosto, 2011, pg. 263-271 disponível em http://www.scielo.br/pdf/paideia/v21n49/14.pdf . Acesso em 09 ago 2015.

CAMPOS, Márcia Zendron. A PRÁTICA NOS CURSOS DE LICENCIATURA: reestruturação curricular da formação inicial. São Paulo, 2006. Tese de doutorado.

CESÁRIO, M. Formação de professores de Educação Física da Universidade Estadual de Londrina: tradução do projeto curricular pelos professores. Tese de Doutorado UFSCar. São Carlos/SP, 2008 disponível em http://www.dominiopublico.gov.br/download/texto/cp113854.pdf

CLAUDINO-KAMAZAKI, S.G. Práxis na formação docente: principais tendências na formação acadêmica atual. UFPR. Dissertação de Mestrado, 2013.

DENTZ, V.V. Elementos para uma crítica ontológica ao relativismo epistemológico nas “teorias" pós-críticas em educação. Atos de Pesquisa em Educação - PPGE/ME FURB 357 ISSN 1809-0354 v. 6, n. 2, p. 356-372, mai./ago. 2011.

GONÇALVES, E. A. N. Educação e Neopragmatismo: A questão da verdade em Rorty e suas repercussões no campo da Educação. UFRJ, 2009. Tese de Doutorado.

HELLER, A. Sociologia de la vida cotidiana. 4ª Edição. Barcelona. Península, 1994.

MARX, K. O capital - Crítica da Economia Política. Volume VI. Livro Terceiro. Rio de Janeiro: Civilização Brasileira, 1981.

MELO, G.F. Tornar-se professor: a formação desenvolvida nos cursos de Física, Matemática e Química da Universidade Federal de Uberlândia. Tese de Doutorado UFG. Goiânia, 2007 disponível em http://www.fe.ufg.br/uploads/6/original_Tese\%20Geovana\%20Ferreira.pdf 
MORAES, M.C.M. Recuo da teoria: dilemas na pesquisa em educação. In: Intelectuais, conhecimento e espaço público; anais da $24^{a}$ Reunião Anual da ANPED. Caxambú, ANPED, 2001. CD-ROM.

MORAES, M. C. M. (org.). Iluminismo às avessas: produção de conhecimento e políticas de formação docente. Rio de Janeiro: DP\&A, 2003.

MORAES, M. C. M. TORRIGLIA, P.L. Sentidos do ser docente e da construção de seu conhecimento. In MORAES, M. C. M. (org.) Iluminismo às avessas: produção de conhecimento e políticas de formação docente. Rio de Janeiro: DP\&A, 2003.

MORADILLO, E.F. A dimensão prática na Licenciatura em Química da UFBA: Possibilidades para além da formação empírico-analítica. Tese de Doutorado UFBA. Salvador/Bahia, 2010 disponível em https://twiki.ufba.br/twiki/pub/PPGEFHC/DissertacoesPpgefhc/Tese_EDILSON_FORT UNA_DE_MORADILLO.pdf

OCDE. Como alguns estudantes superam as dificuldades do ambiente socioeconômico? PISA EM FOCO 5/2011 (Junho). OCDE. 2011. Disponível em: http://download.inep.gov.br/acoes_internacionais/pisa/pisa_em_foco/2011/pisa_em_foc o_n5.pdf. Acesso em: 01/09/2014.

PEREIRA, P.S. A concepção de prática na visão de Licenciandos de Matemática. Tese de Doutorado UNESP Rio Claro. Rio Claro/SP, 2005 disponível em http://www.athena.biblioteca.unesp.br/exlibris/bd/brc/33004137031P7/2005/pereira_ps dr_rcla.pdf

PERES, A.F. Saberes e Identidade Profissional em um curso de formação de professores de Língua Portuguesa. Tese de Doutorado UEL. Londrina/PR, 2007 disponível em http://www.bibliotecadigital.uel.br/document/?view=vtls000123256

PERRENOUD, P. Práticas pedagógicas, profissão docente e formação. Perspectivas Sociológicas. Lisboa: Dom Quixote, 1993. 
Enseigner: Agir dans l'urgence, décider dans l'incertitude. Savoirs et compétences dans un métier complexe. Paris: ESF Editeur, 1996.

Dez novas competências para ensinar. Porto Alegre: Artes Médicas, 1999.

SANTOS JÚNIOR, C. L. A formação de professores em Educação Física: A mediação dos parâmetros teórico-metodológicos. Tese de Doutorado UFBA. Salvador, 2005 disponível em http://www.lepel.ufba.br/TESES/A\%20FORMA\%C7\%C3O\%20DE\%20PROFESSORE S\%20DE\%20E\%20F\%20-

\%20A\%20MEDIA\%C7\%C3O\%20DOS\%20PAR\%C2METROS\%20TE\%D3RICO\%20 METODOL\%D3GICOS\%20-\%20CLAUDIO\%20LIRA.pdf

SAVIANI, Dermeval. Pedagogia Histórico-crítica primeiras aproximações. Autores associados, 2003.

SCHÖN, Donald A. The reflective practitioner: How professionals think in action. Basic books, 1983.

SCHÖN, D. Formar professores como profissionais reflexivos In: NÓVOA, A (Org). Os professores e sua formação. Dom Quixote, Lisboa, 1992.

Formar professores como profissionais reflexivos. In: NÓVOA, A. (Org.). Os professores e a sua formação. 3. Edição, Lisboa: Dom Quixote, 1997.

Educando o profissional reflexivo: um novo design para o ensino e aprendizagem. Porto Alegre: Artes Médicas, 2000.

SILVA, C.R.; SILVA, L.F.; MARTINS, S.T.F. Marx, ciência e educação: a práxis transformadora como mediação para a produção do conhecimento, s/d. vl 1, nro 1, p 7-18.

TARDIF, M. Saberes docentes e formação profissional. Petrópolis: Vozes, 2002. 
VAZQUEZ, A.S. Filosofia da Práxis. CLACSO. Expressão Popular, 2007.

\begin{abstract}
${ }^{1}$ Sonia Regina Landini- Doutora pela PUC/SP- História e Filosofia (Trabalho e Educação). Professora junto ao setor de educação da UFPR. Email: slandini@uol.com.br.

${ }^{2}$ Silvana Galvani Claudino-Kamazaki - Mestra em Educação pela UFPR (Tecnologias, Trabalho e Educação) e doutoranda em Educação Escolar pela UNESP/Araraquara (Teorias Pedagógicas, Trabalho Educativo e Sociedade).E-mail: silkamazaki@gmail.com

${ }^{3} \mathrm{O}$ termo resiliência foi emprestado da Física pela Psicologia. Originalmente se refere à característica física de alguns materiais de voltarem à sua forma original após terem sofrido impactos do ambiente (o que remete), na psicologia, à capacidade do indivíduo resistir às dificuldades [...] A OCDE, ao analisar e propor processos avaliativos tais como PISA (Programme for International Student Assessment), irá afirmar que os estudantes "[...] resilientes são aqueles que provêm de um ambiente socioeconômico relativamente desfavorável e alcançam altos desempenhos, do ponto de vista dos padrões internacionais" (OCDE, 2011, p.03).
\end{abstract}

RECEBIDO EM: Setembro de 2015

APROVADO EM: Abril de 2016 